Free Communication

Haemostasis 1981;10(Suppl. 1):172

\title{
Haemophilia in Yugoslavia
}

\begin{tabular}{|l|l|l|}
\hline J. & Jonce & Nedelkoski \\
\hline
\end{tabular}

Faculty of Medicine, Skopje, Yugoslavia

J. Nedelkoski, Med. Fakulteta, Vodnjanska 17, 9100 Skopje (Yugoslavia)

The distribution, types and medical care of haemophilia in different parts of Yugoslavia are presented. 